\title{
Experimental and Theoretical Studies on Flexural Performance of Stainless Steel Reinforced Concrete Beams
}

\author{
Qingfu Li, ${ }^{1,2}$ Wei Guo $\mathbb{D}^{1,2}$ Chenhui Liu, ${ }^{1,2}$ Yihang Kuang $\mathbb{D}^{1,2}$ and Huitao Geng ${ }^{3}$ \\ ${ }^{1}$ Research Center on Levee Safety and Disaster Prevention, Ministry of Water Resources, Zhengzhou 450003, China \\ ${ }^{2}$ School of Water Conservancy Engineering, Zhengzhou University, Zhengzhou 450001, China \\ ${ }^{3}$ Yellow River Water Conservancy Technical Institute, Kaifeng 475004, China \\ Correspondence should be addressed to Yihang Kuang; kuangyihang@gs.zzu.edu.cn
}

Received 5 December 2019; Revised 16 May 2020; Accepted 25 May 2020; Published 27 June 2020

Academic Editor: Behzad Nematollahi

Copyright (C 2020 Qingfu Li et al. This is an open access article distributed under the Creative Commons Attribution License, which permits unrestricted use, distribution, and reproduction in any medium, provided the original work is properly cited.

\begin{abstract}
In this paper, the flexural characteristics of stainless steel (SS) reinforced concrete beams are studied and analyzed. We mainly focus on their crack mode, failure mode, load-deflection curve, and bearing capacity. Six beams with test parameters, including the diameter of reinforcement, the type of the reinforcement, and the stirrup spacing, were tested in 4-point bending. The test results indicate that the failure mode of SS reinforced concrete beam can be divided into three stages: elastic stage, cracking stage, and failure stage. The midspan section deformation of SS reinforced concrete beam conforms to the assumption of plane section. Under the same reinforcement condition, the normal section and the oblique section bearing capacities of the SS reinforced concrete beams are significantly higher than those of the ordinary reinforced concrete beams. In addition, the prediction of cracking moment and bearing capacity calculated by ACI 318-14 and GB 50010-2010 was also evaluated. The calculation results of the two codes were safe and conservative, and GB 50010-2010 provided more accurate prediction of cracking moments. Furthermore, to verify the reliability of the test results, finite element models were established and the analytical results corroborated well with the test results.
\end{abstract}

\section{Introduction}

SS has many outstanding properties that can be popularized in engineering construction. Due to its excellent ductility, durability, and recyclability, it is possible to create a tougher, more environmentally friendly SS construction $[1,2]$. With its excellent plasticity and extensibility, it provides more possibilities for the appearance, color, and style of the engineering structure. In addition, SS has excellent corrosion resistance and high chemical stability, so SS reinforcement can be used for bridges, coastal equipment, and buildings.

Corrosion resistance plays a vital role in the stability of reinforced concrete structures $[3,4]$. The occurrence of steel corrosion problems is accompanied by high maintenance costs and maintenance intervals. Many researches on corrosion resistance of SS reinforcement in concrete have been carried out. At a certain concentration of chloride ion, the passivation film of SS reinforced concrete structure will be destroyed and the durability will be threatened. Chloride ion concentration has different effects on SS and conventional carbon steel; the acceptable limit of chloride ion concentration of SS reinforcement is 10 times that of carbon reinforcement [5]. When exposing ordinary steel reinforcements and SS reinforcements to chlorides, the damage of ordinary steel reinforcements is more serious than that of SS reinforcements [6-8]. It was found that the presence of chloride affects the electronic properties of reinforced concrete structure passivation films, and the austenitic SS reinforcements have better electronic and electrochemical properties than duplex SS reinforcements. Also, SS alloy can effectively enhance the slip-resistance, hardness, and corrosion resistance of ordinary stainless steel, so as to solve the problem of steel corrosion, but it was also affected by factors such as chloride ion concentration, corrosion inhibitor, and cold work levels [9-13]. Based on the research above, it can be concluded that the corrosion 
resistance of SS reinforced concrete structure is enough to increase by an order of magnitude compared with conventional carbon steel.

On the other hand, many researchers have studied SS mechanical properties, residual stress, high-temperature properties, tensile properties, and so on [14-23]. In the uniaxial tensile test at room temperature, SS does not have a well-defined yield point and shows great strain hardening behavior. In addition, the cold-forming process has a certain influence on the mechanical properties of SS. Through the cold-forming process, the nominal yield stress and ultimate tensile stress of SS increase and the elongation decreases.

Recently, some research on the structural properties of SS reinforced concrete structures has been reported. Some studies showed that replacing carbon steel reinforcements with SS reinforcements had little effect on the bonding property [24-26]. Hassanein and Silvestre [27] studied the bending mechanical properties of tilted duplex SS beams using a finite element model for analysis and concluded that the bending prediction provided by EN 1993-1-4 is conservative. Shamass et al. $[28,29]$ provided several prediction methods for bending performance of SS composite beams based on the continuous strength method.

However, there is currently no experimental investigation of the flexural performance of SS reinforced concrete structures. In this paper, two sets of specimens were manufactured and tested. The type (SS reinforcement and ordinary reinforcement) and diameter $(6.5,12$, and $16 \mathrm{~mm})$ of the reinforcement were considered as variables. Moreover, based on the design theory of reinforced concrete flexural members and the experimental results, the prediction equations of the Chinese and American codes for the flexural performance were evaluated. Meanwhile, finite element models were developed to verify and predict the experimental results.

\section{Design Theory of Reinforced Concrete Flexural Members}

The probability limit condition design methods used in the current Chinese code GB 50010-2010 [30] and American code ACI 318-14 [31] divide the limit state of engineering structures into two types: ultimate limit states and serviceability limit states. When designing the reinforced concrete members, the bearing capacity should be calculated according to the ultimate limit states to ensure safety and reliability. First, the calculation of bearing capacity of concrete flexural members mainly includes the calculation of the bending capacity of the normal section and the calculation of the shear capacity of the oblique section. Second, it is also necessary to design the flexural members according to the serviceability limit states. This is mainly to check the deformation and crack resistance or crack width, to ensure that the members can be used normally. The calculation method of the bearing capacity of the Chinese code and the American code is the same, and the calculation method of the cracking moment is different. The rectangular section of the specimens was taken as an example to illustrate the design method of reinforced concrete flexural members.
2.1. Bending Capacity of Normal Section. The theoretical ultimate moment represents the bending capacity of the normal section, which is proposed by

$$
M_{\mathrm{u}, \mathrm{c}}^{C}=\alpha_{\mathrm{s}} f_{\mathrm{c}} b h_{0}^{2} \text {, }
$$

where $\alpha_{\mathrm{s}}$ is the section resistance moment coefficient, $f_{\mathrm{c}}$ is the design value of concrete axial compressive strength, $b$ is the width of the rectangular section, and $h_{0}$ is the effective height of the section.

2.2. Shear Capacity of Oblique Section. To avoid brittle failure, the number of stirrups in the design should meet the construction requirements. The six beams in this test were equipped with stirrups and were not equipped with bent reinforcements. The ultimate shear capacity of the beam is composed of the shearing force of the concrete and the shearing force of the stirrups. Therefore, the basic calculation method for the shear capacity of the oblique section of the beams is presented in

$$
V_{\mathrm{u}}=V_{\mathrm{c}}+V_{\mathrm{sv}}
$$

where $V_{\mathrm{u}}$ is the ultimate shear capacity of the oblique section, $V_{\mathrm{c}}$ is the shear capacity of concrete, and $V_{\mathrm{sv}}$ is the shear capacity of the stirrups.

2.3. Cracking Moment. The calculation of the cracking moment in the Chinese code and the American code is different. Equation (3) shows the calculation method of theoretical concrete cracking moment in ACI 318-14:

$$
M_{\mathrm{cr}, \mathrm{c}}^{A}=\frac{f_{\mathrm{r}} I_{\mathrm{g}}}{y_{\mathrm{t}}},
$$

where $M_{\mathrm{cr}, \mathrm{c}}^{A}$ is the theoretical value of concrete cracking moment. $f_{\mathrm{r}}$ is the flexural tensile strength of concrete, $f_{\mathrm{r}}=0.62 \sqrt{f_{\mathrm{c}}^{\prime}}, f_{\mathrm{c}}^{\prime}$ is the compressive strength of the concrete cylinder test block, and its conversion relationship with the cubic compressive strength $f_{\mathrm{cu}}$ is $f_{\mathrm{c}}^{\prime}=0.8 f_{\mathrm{cu}} . I_{\mathrm{g}}$ is the sectional resistance moment on the centroid axes, regardless of the area of the reinforcement. $y_{\mathrm{t}}$ is the distance between the centroidal axis and the edge of tensile concrete.

As is shown in equation (4), the theoretical value of the cracking moment in GB 50010-2010 is related to the strength and size of reinforcement and concrete:

$$
M_{\mathrm{cr}, \mathrm{c}}^{C}=\gamma_{\mathrm{m}} \alpha_{\mathrm{ct}} f_{\mathrm{tk}} W_{0},
$$

where $M_{\mathrm{cr}, \mathrm{c}}^{C}$ is the theoretical value of concrete cracking moment, $\gamma_{\mathrm{m}}$ is the plastic coefficients of section modulus, $\alpha_{\mathrm{ct}}$ is concrete tensile stress control coefficient, $f_{\mathrm{tk}}$ is the standard value of concrete tensile strength, and $W_{0}$ is the transformed section modulus to the edge of tensile concrete calculated by

$$
W_{0}=\frac{I_{0}}{h-y_{0}},
$$

where $I_{0}$ is the sectional resistance moment on the centroid axes, $y_{0}$ is the distance between the transformed section 
center of gravity and compression edge of section, and $h$ is the height of the section.

\section{Experimental Program}

3.1. Materials. The reinforcement used in the six beams included SS reinforcement and ordinary steel reinforcement. As is shown in Figure 1, the SS reinforcement was the $022 \mathrm{Cr} 22 \mathrm{Ni} 5 \mathrm{Mo} 3 \mathrm{~N}$ SS reinforcement produced by Shanxi Taigang Stainless Steel Co., Ltd., which was available in three types of diameter: $6.5 \mathrm{~mm}, 12 \mathrm{~mm}$, and $16 \mathrm{~mm}$. Ordinary steel reinforcement adopted HRB335 thread reinforcement of $12 \mathrm{~mm}$ and $16 \mathrm{~mm}$ diameter and HPB335 round reinforcement of $6.5 \mathrm{~mm}$ diameter produced by Anyang Iron and Steel Co., Ltd. According to Chinese code GB/T 2282010 [32], two kinds of steel reinforcement were tested under uniaxial tension at room temperature.

Table 1 shows the material properties of steel reinforcement. The elongation of SS reinforcement is greater than $30 \%$. Compared with ordinary steel reinforcement, SS reinforcement has the characteristics of higher strength, higher yield ratio, greater elongation, and lower elastic modulus. The mechanical properties and process properties of SS reinforcement meet the requirements for the forming and structural use of concrete components. Table 2 presents the concrete mix proportion, and the specific design strength of concrete was $30 \mathrm{MPa}$.

3.2. Experimental Design. Figure 2 shows the six specimens and their production process. There were two SS reinforced concrete flexural beams (Nos. BKW1 and BKW2), two SS reinforced concrete shear beams (Nos. BKJ1 and BKJ2), one ordinary reinforced concrete flexural beam (No. PKW1), and one ordinary reinforced concrete shear beam (No. PKJ1). Figure 3 shows the details of longitudinal reinforcement. All beams were designed with a length of $2400 \mathrm{~mm}$, and a rectangular cross-sectional area of $150 \times 300 \mathrm{~mm}$. The clear span of the beam was $1800 \mathrm{~mm}$, and the length of the pure bending segment was $600 \mathrm{~mm}$.

Table 3 shows the types and specifications of the steel reinforcements of each beam in detail. The diameter of the tensile reinforcement used in the flexural beam was $12 \mathrm{~mm}$, and the diameter of the tensile reinforcement used in the shear beam was $16 \mathrm{~mm}$.

Standard cube blocks with a side length of $150 \mathrm{~mm}$ were reserved when constructing the beams, and the blocks and the beams were maintained in the same condition for examining the concrete compressive strength of the specimens. The average values of concrete compressive strength of the blocks are shown in Table 3.

3.3. Experimental Method. The positions of pressure sensor, LVDTs, strain gauges, and loading points are shown in Figures 4 and 5. The quasi-static graded loading method was adopted to test the flexural behavior of all specimens. A compression testing machine with total capacity of $2000 \mathrm{kN}$ was used to apply the load to a distributive girder. The steel distributive girder distributed concentrated

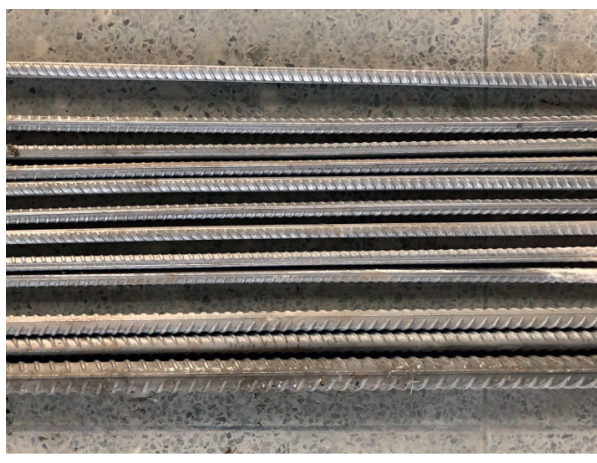

FIGURE 1: Stainless steel reinforcement.

loads on the two trisection points of the top of the beam. The test adopted graded loading, and all beams were preloaded to $20 \mathrm{kN}$ and then unloaded. Before the loading reached $80 \%$ of the theoretical cracking load of the beam, the ratio of each load stage was $5 \%$ of the theoretical ultimate load, and the load value of each stage was no more than $5 \mathrm{kN}$ when approaching cracking load. After the occurrence of first crack, the load value of each stage was $10 \%$ of the theoretical ultimate load, and when approaching the theoretical ultimate load, the loading rate was slowed down. The load was maintained for 5 minutes after each stage of loading, while the crack width was recorded with crack observation apparatus with an accuracy of $0.02 \mathrm{~mm}$, and the occurrence and development of cracks were observed.

Pressure sensor was used to observe the applied load. To monitor the deflection of the beam, five LVDTs with a range of $50 \mathrm{~mm}$ were arranged along the longitudinal direction of the beam. As is shown in Figure 4, the positions of the LVDTs were, respectively, in the midspan of the beam, the two loading points, and the two center points of the support. The net deflection of the beams was the difference between the midspan displacement and the settlement of the support measured by the LDVT.

To verify the assumption that the deformation of the section conforms to the plane section, a total of 5 strain gauges in total were used in the midspan of the beam to observe the strain distribution along the height. The heights at which the strain gauges were located (the distance from the compression edge of the beam) were $0 \mathrm{~mm}, 75 \mathrm{~mm}$, $150 \mathrm{~mm}, 225 \mathrm{~mm}$, and $300 \mathrm{~mm}$, respectively.

\section{Experimental Results and Discussion}

4.1. Load-Deflection Curves and Failure Modes. Figure 6(a) shows the load-deflection curves for the midspan of the three flexural beams. The beams BKW1 and BKW2 and the beam PKW1 all showed ductile failure. The deflection of the beam continued to increase after yield, while the load slowly increased. Figure 6(b) presents the loaddeflection curve of the midspan of the three shear beams. The ordinary reinforced concrete shear beam PKJ1 showed ductile failure, and the deflection continued to increase after the beam yielded, while the load increased slowly. The ultimate bearing capacity of BKW1 and BKW2 was $140 \mathrm{kN}$, the 
TABLE 1: Mechanical properties of reinforcements.

\begin{tabular}{|c|c|c|c|c|c|}
\hline Type of reinforcements & Diameter $(\mathrm{mm})$ & Yield strength (MPa) & Tensile strength $(\mathrm{MPa})$ & Elongation (\%) & $\begin{array}{l}\text { Elastic modulus } \\
\left(10^{5} \mathrm{~N} / \mathrm{mm}\right)\end{array}$ \\
\hline \multirow{3}{*}{ SS reinforcement } & 6.5 & 595 & 800 & 32.5 & 1.41 \\
\hline & 12 & 660 & 830 & 37.8 & 1.41 \\
\hline & 16 & 640 & 795 & 33.9 & 1.51 \\
\hline \multirow{3}{*}{ Ordinary steel reinforcement } & 6.5 & 280 & 430 & 29.7 & 2.12 \\
\hline & 12 & 380 & 530 & 30.7 & 2.30 \\
\hline & 16 & 400 & 555 & 28.7 & 2.22 \\
\hline
\end{tabular}

TABle 2: Concrete mix design.

\begin{tabular}{lcccccc}
\hline Water-binder ratio & Sand ratio $(\%)$ & Cement $(\mathrm{kg})$ & Sand $(\mathrm{kg})$ & Gravel $(\mathrm{kg})$ & Water $(\mathrm{kg})$ & Water reducing agent $(\mathrm{kg})$ \\
\hline 0.49 & 37 & 350 & 719 & 1173 & 171.5 & 2.7 \\
\hline
\end{tabular}

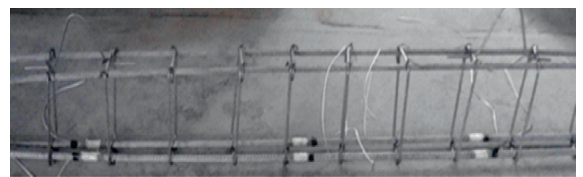

(a)

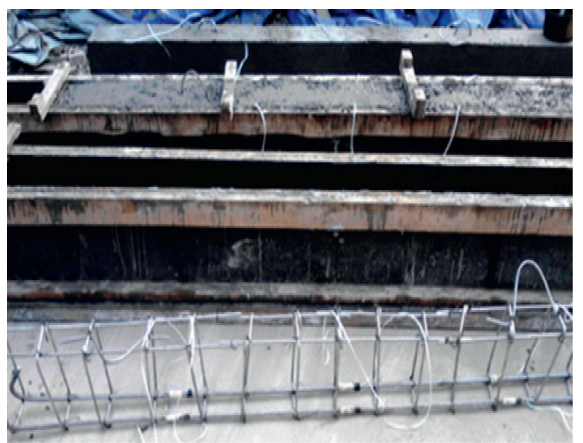

(c)

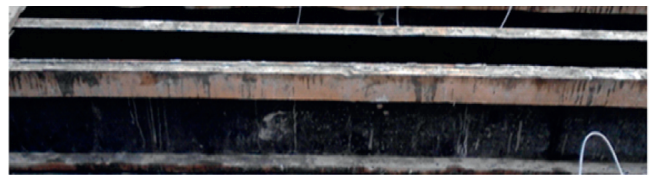

(b)

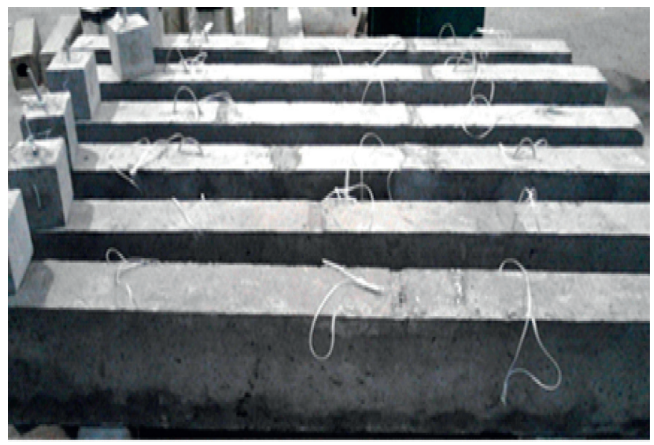

(d)

Figure 2: Photographs of the specimens: (a) reinforcement cage; (b) formwork; (c) production process; (d) cured specimens.

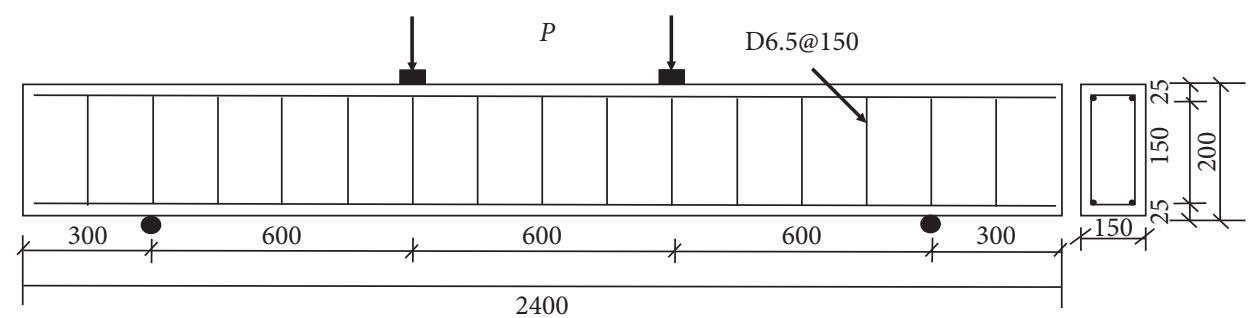

Figure 3: Details of longitudinal reinforcement (all dimensions in $\mathrm{mm}$ ).

ultimate bearing capacity of PKW1 was $100 \mathrm{kN}$, and the ratio of ultimate bearing capacity of the two types was 1.40 . The shear beams BKJ1 and BKJ2 of SS reinforcement showed brittle failure. When the beam was damaged, the tensile reinforcement had not yielded yet, but the concrete of the compression section was crushed, causing the beam to suddenly break. The ultimate bearing capacity of BKJ1 and BKJ2 was $185 \mathrm{kN}$, the ultimate bearing capacity of PKJ1 was
$140 \mathrm{kN}$, and the ratio of ultimate bearing capacity of the two types was 1.32 .

Figure 7 presents photographs and crack patterns of all beams after damage. Under the same load, the crack width of shear beam was significantly smaller than that of the flexural beam. The reason might be that the higher reinforcement ratio of the shear beams controlled the development of the crack width. The failure modes of the two kinds of reinforced 
TABle 3: Types and specifications of the steel reinforcements.

\begin{tabular}{|c|c|c|c|c|c|}
\hline Specimen & $\begin{array}{l}\text { Type of steel } \\
\text { reinforcement }\end{array}$ & $\begin{array}{l}\text { Compression } \\
\text { reinforcement }\end{array}$ & $\begin{array}{l}\text { Tensile } \\
\text { reinforcement }\end{array}$ & Stirrup & $\begin{array}{c}\text { Average of concrete compressive } \\
\text { strength }(\mathrm{MPa})\end{array}$ \\
\hline BKW1 & \multirow{4}{*}{ SS reinforcement } & $2 \varnothing 6.5$ & $2 \varnothing 12$ & $\begin{array}{c}\varnothing 6.5 @ \\
150\end{array}$ & 41.92 \\
\hline BKW2 & & $2 \varnothing 6.5$ & $2 \varnothing 12$ & $\begin{array}{c}\varnothing 6.5 @ \\
150\end{array}$ & 41.54 \\
\hline BKJ1 & & $2 \varnothing 12$ & $2 \varnothing 16$ & $\begin{array}{c}\varnothing 6.5 @ \\
180\end{array}$ & 41.88 \\
\hline BKJ2 & & $2 \varnothing 12$ & $2 \varnothing 16$ & $\begin{array}{c}\varnothing 6.5 @ \\
180\end{array}$ & 43.41 \\
\hline PKW1 & \multirow{2}{*}{$\begin{array}{l}\text { Ordinary steel } \\
\text { reinforcement }\end{array}$} & $2 \varnothing 6.5$ & $2 \varnothing 12$ & $\begin{array}{c}\varnothing 6.5 @ \\
150\end{array}$ & 40.13 \\
\hline PKJ1 & & $2 \varnothing 12$ & $2 \varnothing 16$ & $\begin{array}{c}\varnothing 6.5 @ \\
180\end{array}$ & 35.77 \\
\hline
\end{tabular}

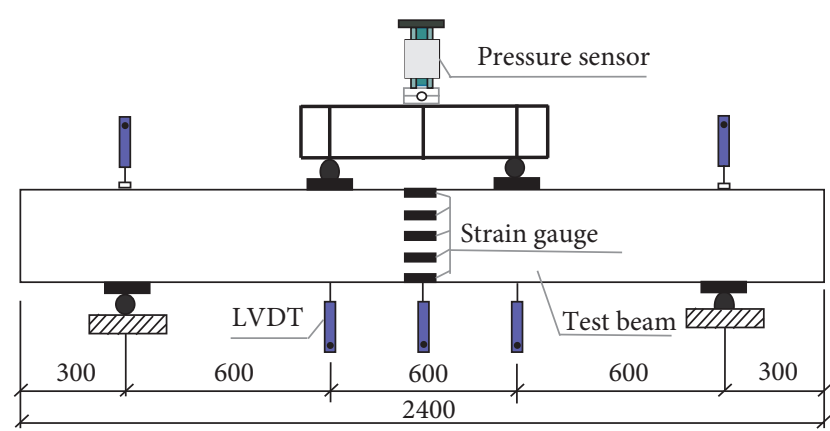

FIgURE 4: Instrumentation setup and load distribution (all dimensions in $\mathrm{mm}$ ).
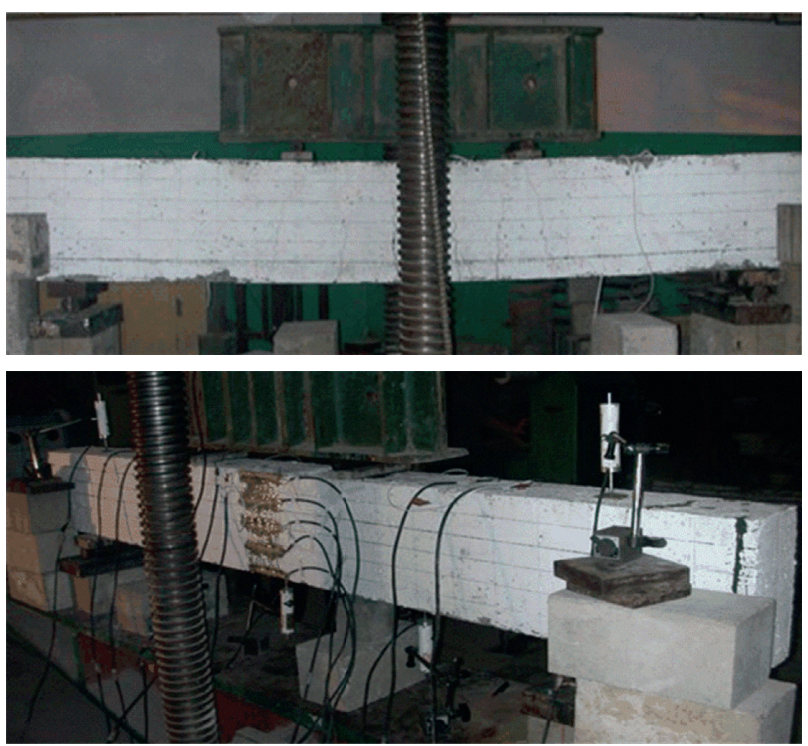

Figure 5: Test setup.

concrete beams are similar; they can be approximately classified into the following three stages:

The first stage is the elastic stage. At the beginning of loading, the stress of reinforcement was small, the deflection changed slowly with the load, and no crack appeared.
The second stage is the cracking stage. At this stage, with development of the cracks, the stiffness of the beams decreased gradually. After reaching the cracking moment, the first vertical crack appeared near the midspan at the bottom of the beam. With increased loading, the cracks slowly developed upward and the crack width slowly increased. When the load reached about $30 \%$ of the beam's ultimate load, several vertical cracks appeared in the pure bending segment. When the load reached about $40 \%$ of the ultimate load, the number of cracks reached a relatively stable value, and these cracks were fine and short and appeared below the neutral axis. As the load continued to increase, the crack still developed slowly, and more vertical cracks appeared between the initial cracks. When the reinforcements approached the yield strength, oblique cracks appeared in the middle and lower parts of the shear-bending segment and developed rapidly toward the loading points and the supports.

The third stage is the failure stage. At this stage, almost no new cracks appeared, and the vertical and oblique cracks developed rapidly upward until the beam was damaged. Among the flexural beams, the width of vertical cracks in the midspan developed sharply and the height extended above the neutral axis after the longitudinal tensile reinforcement yielded. The length of the oblique cracks kept growing, but the width did not change much. When the strain of the concrete near the loading points approached the ultimate compressive strain and was crushed, the bearing capacity was drastically lowered and the beams broke. Before the damage, the deflection of the three beams kept growing, and the growth of the load slowed down. Among the shear beams, after the stirrups of the beam yielded, the oblique cracks developed rapidly from near the supports to the loading points, and their width also increased rapidly. The length and width of the vertical cracks in the midspan developed more slowly. BKJ1 and BKJ2 showed a phenomenon of approximate brittle failure: after the beams yielded, they were quickly destroyed and the deflection did not significantly grow. By contrast, PKJ1 maintained a deflection growth as it approached failure.

4.2. Concrete Strain Distribution. Figure 8 shows the concrete strain distribution along the height at the midspan section of six beams under loads at various levels. The 


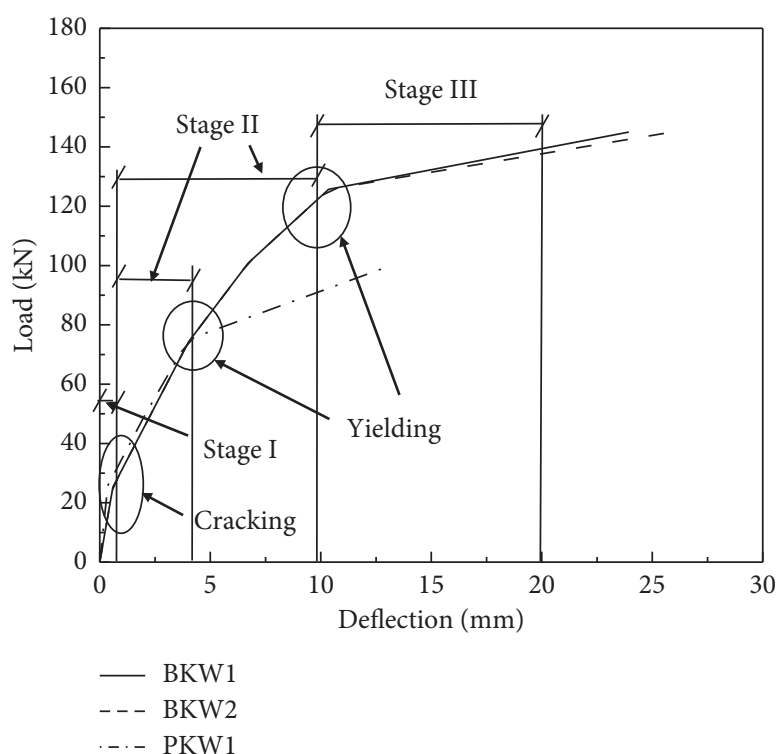

(a)

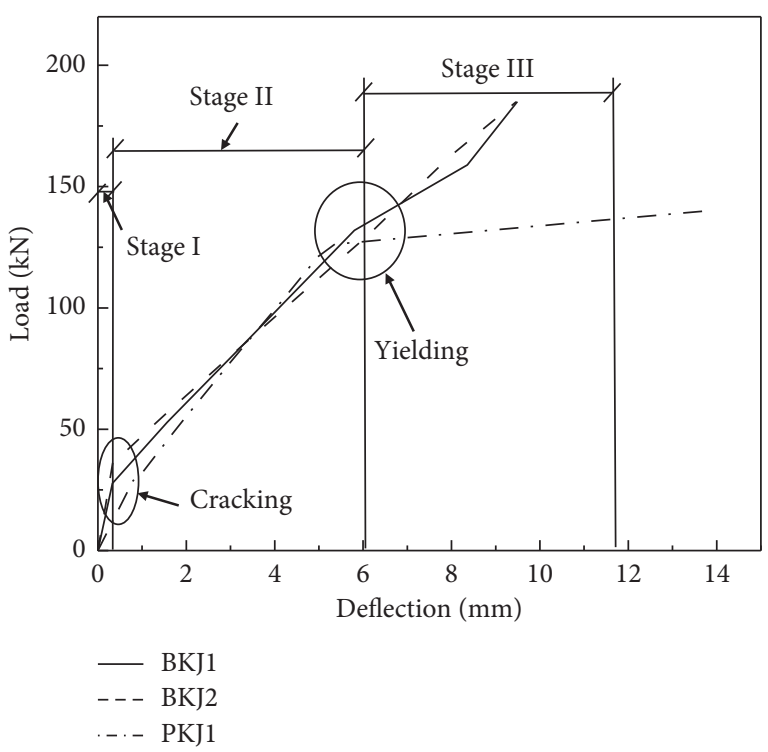

(b)

Figure 6: Load-deflection curves of all tests: (a) flexural beams; (b) shear beams.
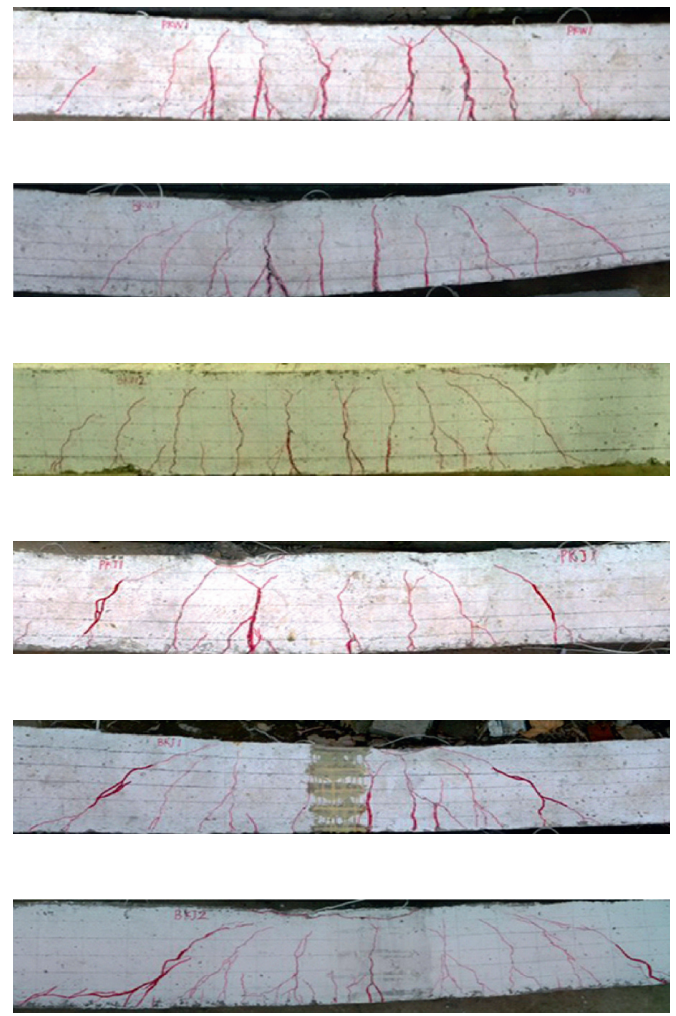

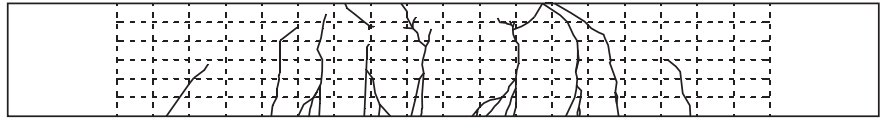

(a)

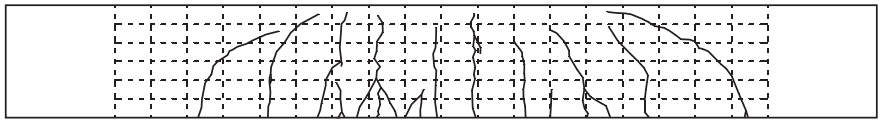

(b)

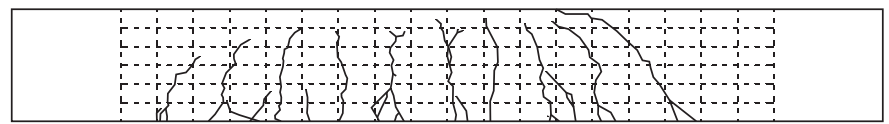

(c)

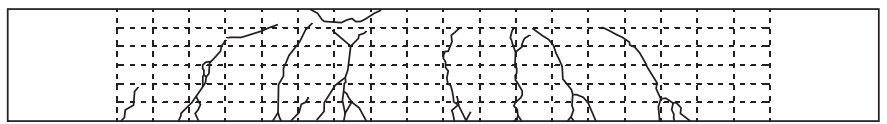

(d)

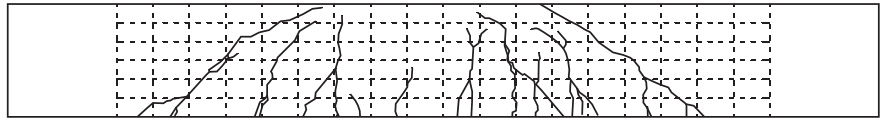

(e)

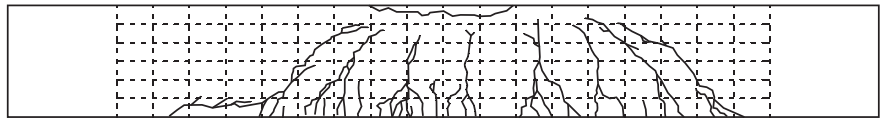

(f)

FIgURE 7: Photographs and crack patterns of all beams. (a) PKW1. (b) BKW1. (c) BKW2. (d) PKJ1. (e) BKJ1. (f) BKJ2.

concrete strain at the moment of failure of the beams was obviously abnormal at the upper and lower edges of the midspan section. The reason was that as the beams were being destroyed, the deformation of the section sharply increased, and the concrete strain was difficult to record. At each stage, the concrete strain in the midspan section of all beams was approximately linearly distributed along the height. It is reasonable to believe that the section 


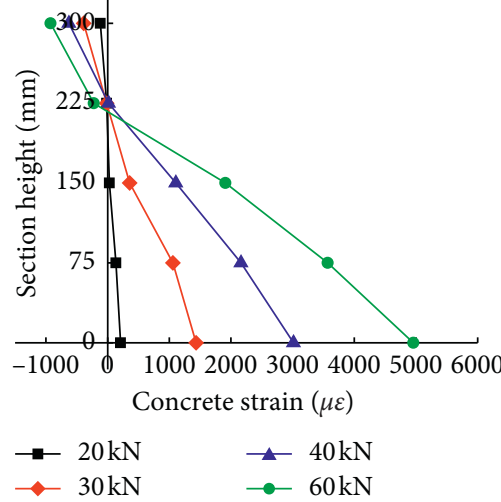

(a)

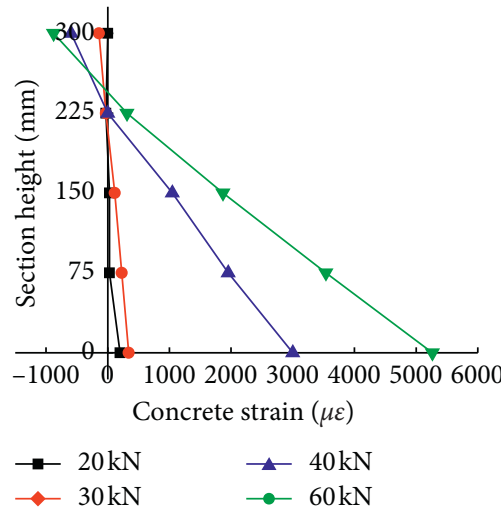

(c)

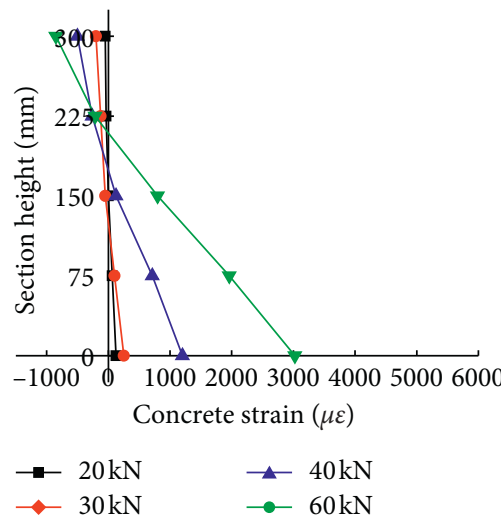

(e)

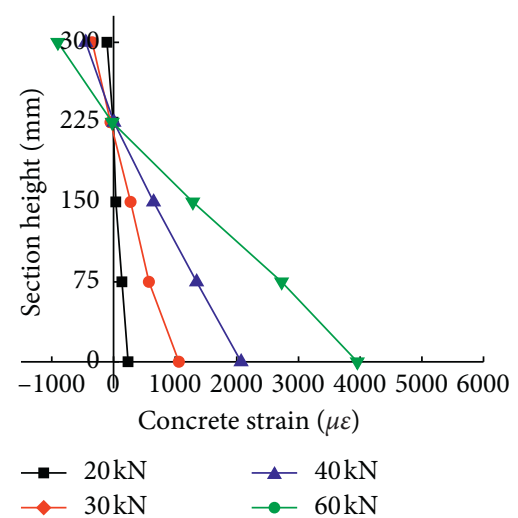

(b)

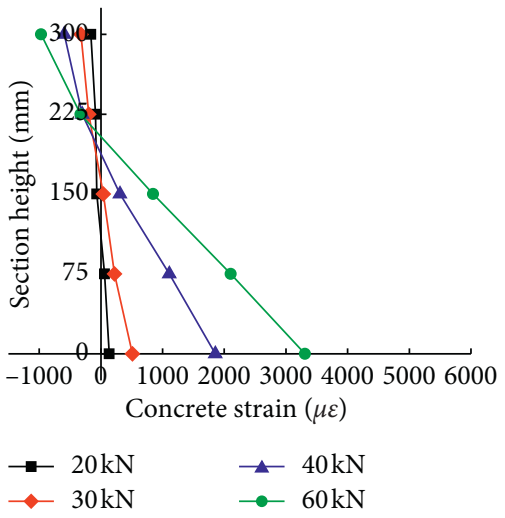

(d)

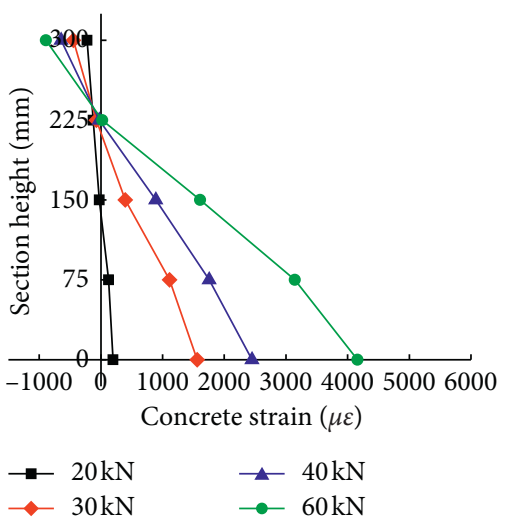

(f)

FIgURE 8: Concrete strain distribution along the height at the midspan section. (a) BKW1. (b) BKW2. (c) PKW1. (d) BKJ1. (e) BKJ2. (f) PKJ1.

deformation of all beams conforms to the assumption of plane section. This is in line with the basic assumptions of material mechanics and provides a basis for the following theoretical calculations of SS reinforced concrete beam.

\subsection{Comparison of Test Results with Theoretical Results}

4.3.1. Cracking Moment. Based on equations (3) and (4), the cracking moment was calculated and is presented along with the experimental values in Figure 9. The experimental cracking moments of both SS and ordinary reinforced concrete beams were greater than the theoretical cracking moments. Among them, the ratio between the experimental cracking moments and the cracking moments calculated according to the code ACI 318-14 is between 1.21 and 1.43, and the average value is 1.328 . Some of the results calculated by the American code deviate significantly from the test results; nevertheless, the overall trend is safe. The ratio between the experimental cracking moments and the cracking moments calculated according to the code GB 50010-2010 is between 1.07 and 1.20, and the average value is 1.138. The Chinese code provides more accurate prediction of the test results. 


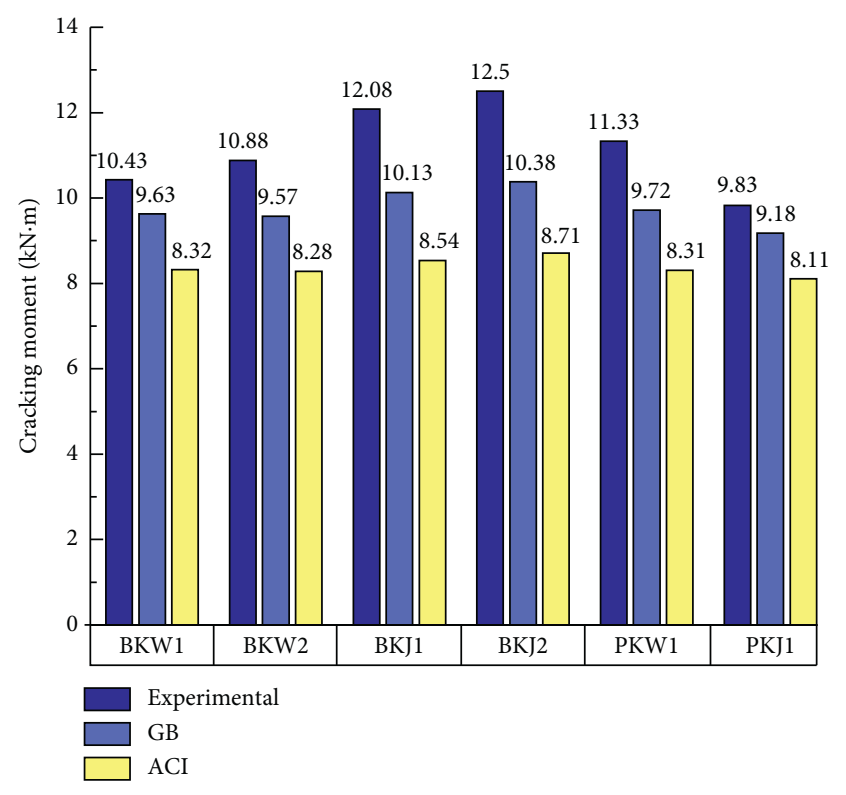

Figure 9: Comparison between experimental and theoretical cracking moments.

4.3.2. Bearing Capacity of the Normal Section. The theoretical ultimate moments of the three flexural beams were calculated by equation (1). Figure 10 shows the theoretical value and experimental value of the ultimate moments, which stand for the bearing capacity of normal section. The experimental ultimate moments of SS and ordinary reinforced concrete beams were greater than the theoretical ultimate moments. The average ratio of the experimental ultimate moments to the theoretical ultimate moments of the SS reinforced concrete beam is 1.35 with a dispersion coefficient of 0.068 . It can be concluded that the ultimate moment of normal section of SS reinforced concrete beam calculated by the current code is $35 \%$ safer.

4.3.3. Bearing Capacity of the Oblique Section. The theoretical ultimate shear capacity of the three shear beams is calculated with equation (2). Figure 11 shows a comparison between the experimental and the theoretical ultimate shear capacity, which represents the bearing capacity of oblique section. Under the same reinforcement condition, the average ultimate shear capacity of SS reinforced concrete beams is 1.27 times that of ordinary reinforced concrete beams. The experimental ultimate shear capacity of BKJ1 and BKJ2 is 1.41 times the theoretical value, while the experimental ultimate shear capacity of PKJ1 is 1.13 times the theoretical value. Therefore, equation (2) is conservative for calculating the ultimate shear capacity of SS reinforced concrete beams.

\section{Finite Element Analysis Study}

For finite element analysis study, ABAQUS was used to verify and predict the experimental results. Six beams were modeled, and the analysis results were compared with experimental results for analysis. Figure 12 shows the finite element model in detail. The model avoided the stress concentration at the loading points and the

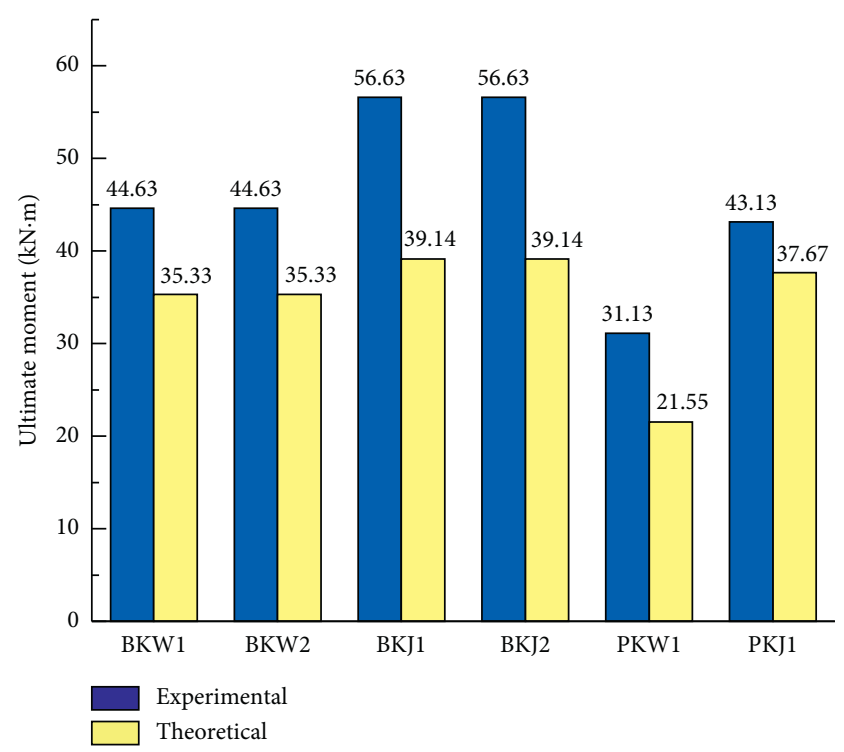

FIgURE 10: Comparison between experimental and theoretical ultimate moments.

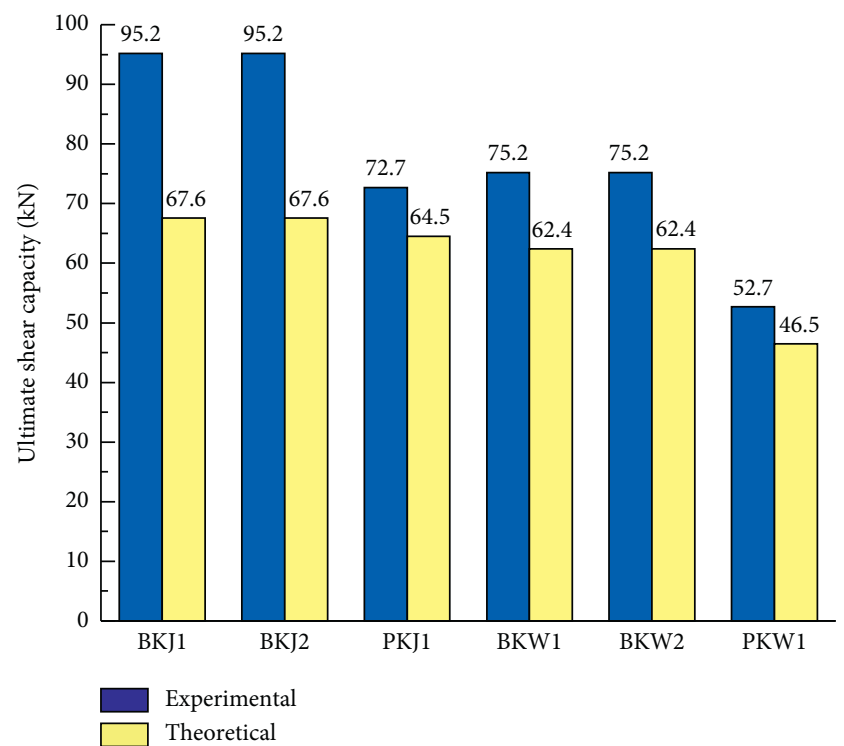

FIgURE 11: Comparison between experimental and theoretical ultimate shear capacity of shear beams.

supports by setting the steel plate, and the loading process was controlled by the displacement. The reinforcements were embedded into concrete. Hexadecimal element shape and structured technique were adopted for mesh controls. Subsequently, the constitutive models used for the three materials of the model were described and the analytical results were discussed.

\subsection{Material Constitutive Models}

5.1.1. Concrete Model. The concrete model adopted the concrete damage plasticity model (CDP model) provided by ABAQUS, and the uniaxial constitutive relationship of 


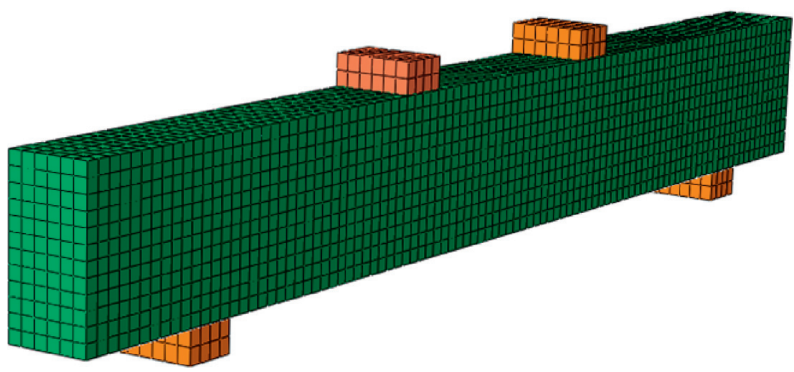

(a)

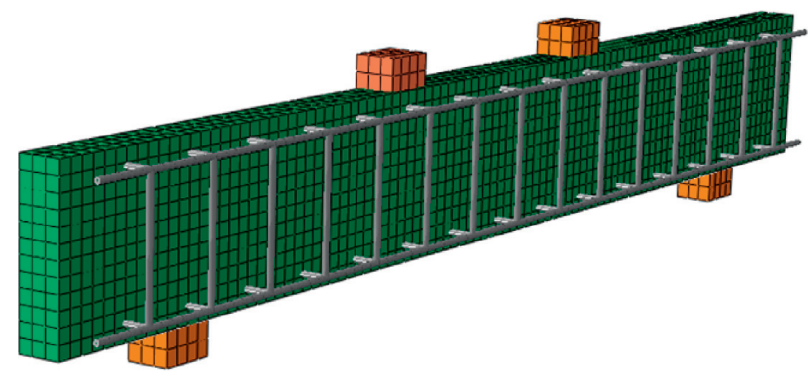

(b)

FIGURE 12: Finite element model in detail.

concrete was provided by GB 50010-2010. The model reflects the phenomenon that the elastic modulus of concrete decreases along with the increase of damage degree. The uniaxial constitutive model could be determined by

$$
\sigma=(1-d) E_{\mathrm{c}} \mathcal{E}
$$

where $d$ is the evolution parameter of concrete under uniaxial loading and $E_{\mathrm{c}}$ is the initial elasticity modulus. When the concrete is under uniaxial tension, $d$ can be determined by the following equations:

$$
\begin{aligned}
& d= \begin{cases}1-\rho_{\mathrm{t}}\left(1.2-0.2 x^{5}\right), & x \leq 1, \\
1-\frac{\rho_{\mathrm{t}}}{\alpha_{\mathrm{t}}(x-1)^{1.7}+x}, & x>1,\end{cases} \\
& x=\frac{\varepsilon}{\varepsilon_{\mathrm{t}, \mathrm{r}}}, \\
& \rho_{\mathrm{t}}=\frac{f_{\mathrm{t}, \mathrm{r}}}{E_{\mathrm{c}} \varepsilon_{\mathrm{t}, \mathrm{r}}}
\end{aligned}
$$

where $\alpha_{\mathrm{t}}$ is the parameter value of the descending section of concrete uniaxial tensile stress-strain curve. $f_{\mathrm{t}, \mathrm{r}}$ is the representative value of concrete uniaxial tensile strength. $\varepsilon_{\mathrm{t}, \mathrm{r}}$ is the peak tensile strain corresponding to the representative value $f_{\mathrm{t}, \mathrm{r}}$ of the uniaxial tensile strength.
When the concrete is under uniaxial compression, $d$ can be determined by the following equations:

$$
\begin{aligned}
& d= \begin{cases}1-\frac{\rho_{\mathrm{c}} n}{n-1+x^{n}}, & x \leq 1, \\
1-\frac{\rho_{\mathrm{c}}}{\alpha_{\mathrm{c}}(x-1)^{2}+x}, & x>1,\end{cases} \\
& \rho_{\mathrm{c}}=\frac{f_{\mathrm{c}, \mathrm{r}}}{E_{\mathrm{c}} \varepsilon_{\mathrm{c}, \mathrm{r}}}, \\
& n=\frac{E_{\mathrm{c}} \varepsilon_{\mathrm{c}, \mathrm{r}}}{E_{\mathrm{c}} \varepsilon_{c, \mathrm{r}}-f_{\mathrm{c}, \mathrm{r}}}, \\
& x=\frac{\varepsilon}{\varepsilon_{\mathrm{c}, \mathrm{r}}}
\end{aligned}
$$

where $\alpha_{\mathrm{c}}$ is the parameter value of the descending section of concrete uniaxial compressive stress-strain curve. $f_{c, r}$ is the representative value of concrete uniaxial compressive strength. $\varepsilon_{\mathrm{c}, \mathrm{r}}$ is the peak compressive strain corresponding to the representative value $f_{\mathrm{t}, \mathrm{r}}$ of the uniaxial compressive strength.

5.1.2. Ordinary Steel Reinforcement Model. Figure 13 shows the ordinary reinforcement model, which is composed of three parts. This model embodies the phenomenon of ordinary steel yield and simplifies its mechanical properties 


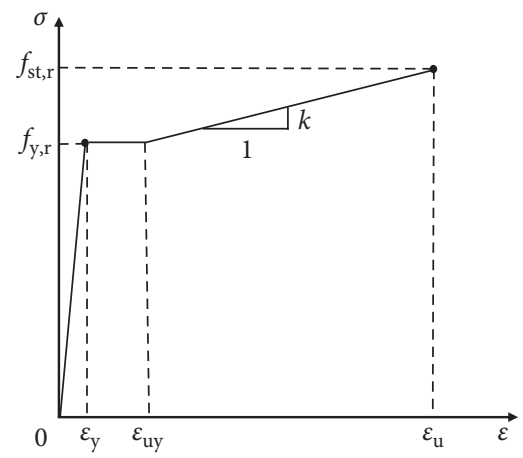

FIGURE 13: Stress-strain curve of steel reinforcement.

into three straight lines. The constitutive relationship is calculated by

$$
\sigma_{\mathrm{s}}= \begin{cases}E_{\mathrm{s}} \varepsilon_{\mathrm{s}}, & \varepsilon_{\mathrm{s}} \leq \varepsilon_{\mathrm{y}}, \\ f_{\mathrm{y}, \mathrm{r}}, & \varepsilon_{\mathrm{y}}<\varepsilon_{\mathrm{s}} \leq \varepsilon_{\mathrm{uy}}, \\ f_{\mathrm{y}, \mathrm{r}}+k\left(\varepsilon_{\mathrm{s}}-\varepsilon_{\mathrm{uy}}\right), & \varepsilon_{\mathrm{uy}}<\varepsilon_{\mathrm{s}} \leq \varepsilon_{\mathrm{u}}, \\ 0, & \varepsilon_{\mathrm{s}}>\varepsilon_{\mathrm{u}},\end{cases}
$$

where $E_{\mathrm{s}}$ is the elastic modulus of reinforcement, $f_{\mathrm{y}, \mathrm{r}}$ is the representative value of the yield strength of reinforcement, $\varepsilon_{\mathrm{uy}}$ is the hardening starting point strain of the steel reinforcement, $\varepsilon_{\mathrm{y}}$ is the yielding strain of reinforcement, $\varepsilon_{\mathrm{u}}$ is the peak strain of reinforcement, $k$ is the slope of reinforcement hardening section, $k=\left(f_{\mathrm{st}, \mathrm{r}}-f_{\mathrm{y}, \mathrm{r}}\right) /\left(\varepsilon_{\mathrm{uy}}-\varepsilon_{\mathrm{u}}\right)$, and $f_{\mathrm{st}, \mathrm{r}}$ is the representative value of the ultimate strength of reinforcement.

5.1.3. SS Reinforcement Model. Ramberg and Osgood [33] first proposed using three parameters to describe the nonlinear relationship between stress and strain. Rasmussen [34] improved the Ramberg-Osgood model, and the improved model better reflected the real stress-strain curve of SS reinforcement. As is shown in Figure 14, the SS reinforcement model adopted the Rasmussen model. The model consists of two parts and can be defined as follows:

$$
\begin{aligned}
\mathcal{\varepsilon} & = \begin{cases}\frac{\sigma}{E_{0}}+0.002\left(\frac{\sigma}{\sigma_{0.2}}\right)^{n}, & \sigma \leq \sigma_{0.2} \\
\frac{\left(\sigma-\sigma_{0.2}\right)}{E_{0.2}}+\varepsilon_{\mathrm{u}}\left(\frac{\sigma-\sigma_{0.2}}{\sigma_{\mathrm{u}}-\sigma_{0.2}}\right)^{m}+\varepsilon_{0.2}, & \sigma>\sigma_{0.2}\end{cases} \\
E_{0.2} & =\frac{E_{0}}{1+0.002 n\left(E_{0} / \sigma_{0.2}\right)}, \\
m & =1+\frac{3.5 \sigma_{0.2}}{\sigma_{u}}, \\
\varepsilon_{0.2} & =\frac{\sigma_{0.2}+0.02}{E_{0}} \\
n & =\frac{\ln 20}{\ln \left(\sigma_{0.2} / \sigma_{0.01}\right)}
\end{aligned}
$$

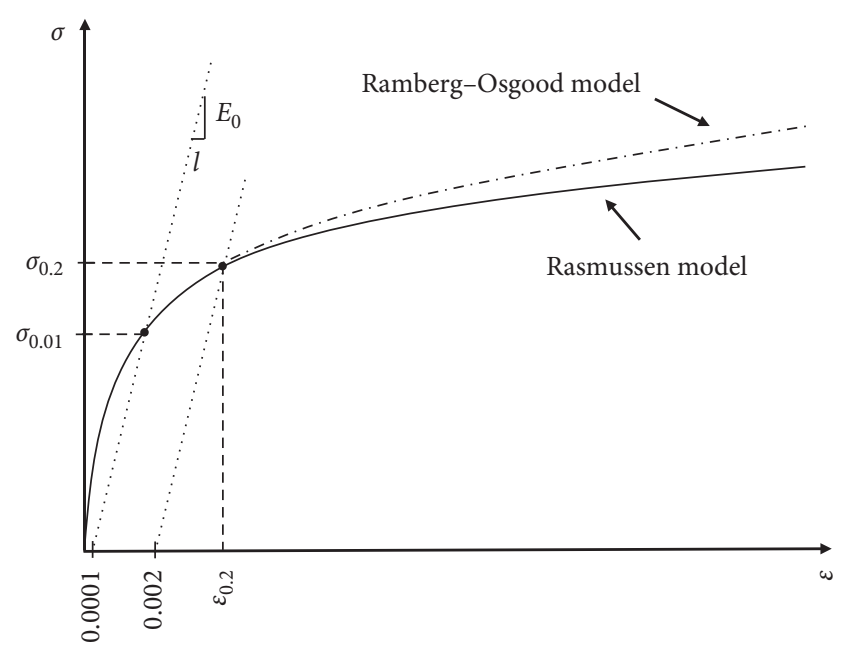

Figure 14: Rasmussen model.

where $n$ is the strain hardening index, $E_{0}$ is the elastic modulus, $\sigma_{0.2}$ and $\sigma_{0.01}$ are the corresponding elastic limit stress values when the residual strain is $0.2 \%$ and $0.01 \%$, respectively, $\sigma_{\mathrm{u}}$ is the ultimate stress, and $\varepsilon_{\mathrm{u}}$ is the ultimate strain.

5.2. Analytical Results and Discussion. In ABAQUS, the tensile damage picture of concrete can be regarded as a crack pattern. Figure 15 shows a typical crack pattern for the finite element models. The first crack occurred at the bottom of the model. Then, the cracks extended from bottom to top and from the supports to the loading points. The crack patterns and their performance in finite element analysis were consistent with the test. This shows that the finite element model can reflect the phenomena of crack patterns of SS reinforced concrete beams.

Figure 16 shows the comparison of analytical load-deflection curves and experimental results for six beams. Among these beams, the results (including initial elastic modulus, cracking load, ultimate load, and load-deflection curve) predicted by the finite element model showed good agreement with the experimental results. It can be seen in Table 4 that the deflection corresponding to cracking load 


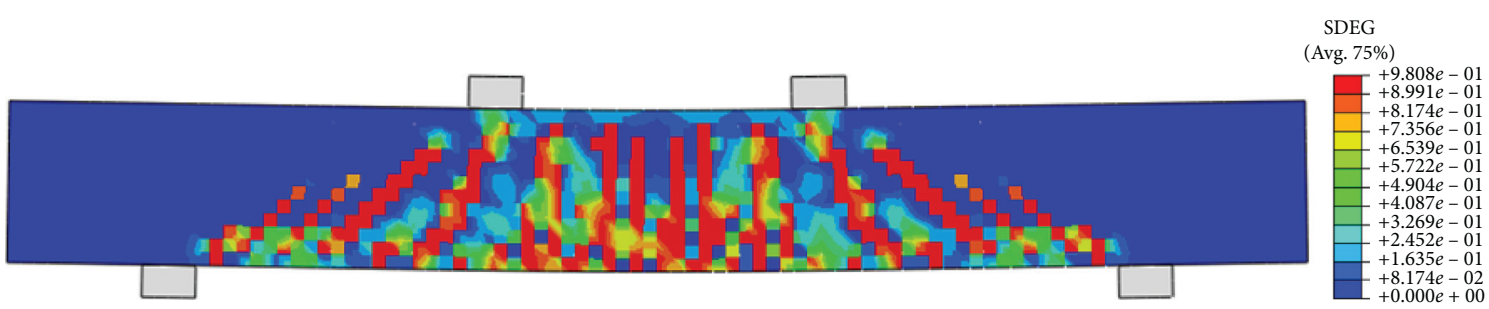

FIGURE 15: Typical crack pattern of finite element models.
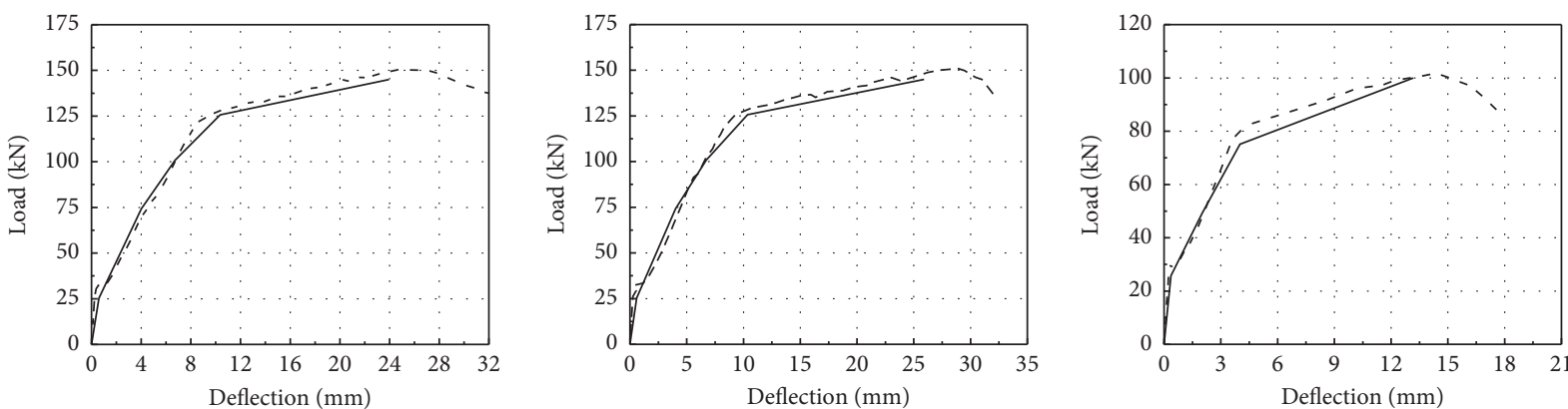

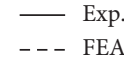

(a)

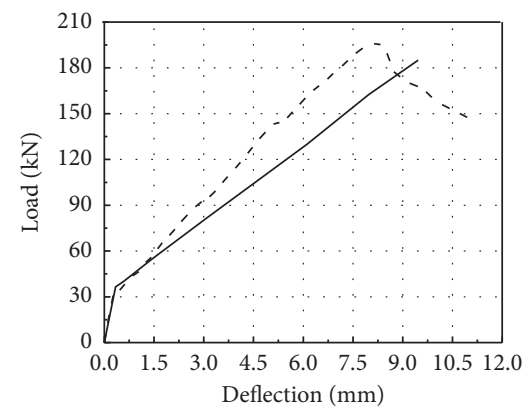

- Exp.

- - - FEA

(d)
- Exp.

-- FEA

(b)

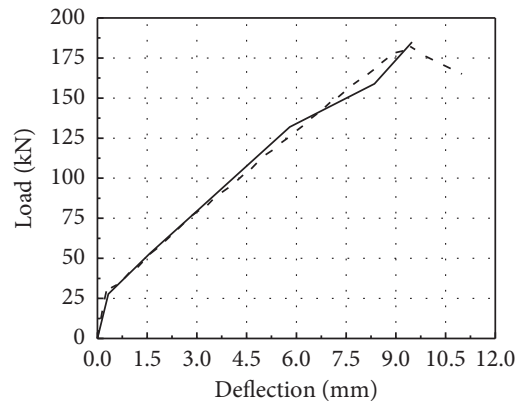

Exp.

(e)

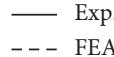

(c)

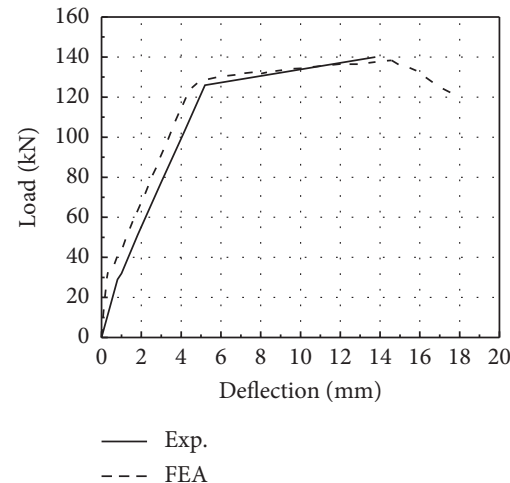

(f)

FIGURE 16: Comparison between experimental and analytical load-deflection curves: (a) BKW1; (b) BKW2; (c) PKW1; (d) BKJ1; (e) BKJ2; (f) PKJ1.

TABle 4: Cracking moment and maximum moment of specimens.

\begin{tabular}{|c|c|c|c|c|c|c|c|c|c|}
\hline \multirow[t]{2}{*}{ Specimen } & \multicolumn{2}{|c|}{$\begin{array}{l}\text { Cracking load } \\
\quad P_{\mathrm{cr}}(\mathrm{kN})\end{array}$} & \multicolumn{2}{|c|}{$\begin{array}{l}\text { Ultimate load } \\
\qquad P_{\mathrm{u}}(\mathrm{kN})\end{array}$} & \multicolumn{2}{|c|}{$\begin{array}{c}\text { Deflection at } \\
\text { ultimate load } \\
\Delta(\mathrm{mm})\end{array}$} & \multirow[t]{2}{*}{$P_{\mathrm{cr}}(\mathrm{FEA}) / P_{\mathrm{cr}}($ Exp. $)$} & \multirow[t]{2}{*}{$P_{\mathrm{u}}($ FEA $) / P_{\mathrm{cr}}($ Exp. $)$} & \multirow[t]{2}{*}{$\Delta($ FEA $) / \Delta($ Exp. $)$} \\
\hline & Exp. & FEA & Exp. & FEA & Exp. & FEA & & & \\
\hline BKW1 & 31.00 & 33.11 & 145.00 & 150.47 & 23.94 & 24.84 & 1.07 & 1.04 & 1.04 \\
\hline BKW2 & 32.50 & 32.79 & 145.00 & 149.46 & 25.90 & 26.40 & 1.01 & 1.03 & 1.02 \\
\hline PKW1 & 34.00 & 30.56 & 100.00 & 101.51 & 13.17 & 13.22 & 0.90 & 1.01 & 1.00 \\
\hline BKJ1 & 36.50 & 32.67 & 185.00 & 182.34 & 9.48 & 9.44 & 0.90 & 0.99 & 1.00 \\
\hline BKJ2 & 39.00 & 34.52 & 185.00 & 195.20 & 9.46 & 8.25 & 0.89 & 1.06 & 0.87 \\
\hline PKJ1 & 29.00 & 32.74 & 140.00 & 138.16 & 13.76 & 14.30 & 1.13 & 0.99 & 1.04 \\
\hline
\end{tabular}


and ultimate load analyzed by the finite element model is close to the test result. The ratio of the cracking load of the analytical value to the experimental value is between 0.89 and 1.13 , and the ratio of the ultimate load of the analytical value to the experimental value is between 0.99 and 1.06. The maximum error of cracking load is $13 \%$, and the maximum error of ultimate load is $6 \%$. This comparison indicates that the model established by the finite element program can sufficiently predict the experimental results.

\section{Conclusions}

In this paper, SS reinforcement and ordinary steel reinforcement were tested under uniaxial tension at room temperature. Then 6 beams of dimensions $150 \mathrm{~mm} \times 300 \mathrm{~mm}, 2400 \mathrm{~mm}$, which consisted of steel reinforcement of different types and diameters, were examined for mechanical behavior. Based on the study above, the following conclusions can be given:

(1) SS reinforcement does not have a well-defined yield point. Compared with ordinary steel reinforcement, SS reinforcement has the characteristics of higher strength, greater yield ratio, greater elongation, and slightly lower elastic modulus. In the flexural and shear tests, SS reinforcements show a good cooperative working mechanism with concrete.

(2) The diversion of concrete strain in the midspan section was approximately linearly distributed along the height. It can be considered that the section deformation of SS reinforced concrete beam conforms to the assumption of plane section.

(3) Compared with ordinary steel reinforced concrete beams, SS reinforced concrete beams had larger ultimate bearing capacity. Under the same reinforcement condition, the ratio of ultimate bearing capacity between two types of steel reinforced concrete beams was 1.40 in the flexural test and 1.32 in the shear test. However, SS reinforced concrete beams are prone to brittle failure due to the high reinforcement ratio.

(4) The experimental cracking moments of both SS and ordinary reinforced concrete beams are greater than the theoretical cracking moment. For the evaluation of cracking moments, ACI 318-14 provided an average of $28.5 \%$ and $35 \%$ safer prediction for SS and ordinary reinforced concrete beams, respectively. GB 50010-2010 provided an average of $15 \%$ and $11.5 \%$ SS for SS and ordinary reinforced concrete beams, respectively. The results calculated by GB 50010-2010 are closer to the experimental results, while ACI 31814 was safer.

(5) The calculation method for the normal section and the oblique section bearing capacity is the same in the American code and the Chinese code. The theoretical bearing capacity for all beams was $1.13 \sim 1.45$ times the experimental results. It is safe to predict the bearing capacity of SS reinforcement flexural members using the existing codes.

(6) The crack patterns and the load-deflection curves obtained from FEA are in good agreement with the experimental results, and the maximum error of ultimate load is $6 \%$. The comparison proves the rationality and feasibility of this paper.

\section{Data Availability}

The data used to support the findings of this study are included within the article.

\section{Conflicts of Interest}

The authors declare no conflicts of interest.

\section{Acknowledgments}

The authors would like to acknowledge the financial support provided by the National Natural Science Foundation of China (No. 51679220) and the Open Project Fund of Research Center on Levee Safety and Disaster Prevention of MMR (No. 2018002).

\section{References}

[1] N. R. Baddoo, "Stainless steel in construction: a review of research, applications, challenges and opportunities," Journal of Constructional Steel Research, vol. 64, no. 11, pp. 1199-1206, 2008.

[2] M. Dundu, "Evolution of stress-strain models of stainless steel in structural engineering applications," Construction and Building Materials, vol. 165, pp. 413-423, 2018.

[3] J. T. Pérez-Quiroz, J. Terán, M. J. Herrera, M. Martínez, and J. Genescá, "Assessment of stainless steel reinforcement for concrete structures rehabilitation," Journal of Constructional Steel Research, vol. 64, no. 11, pp. 1317-1324, 2008.

[4] S. D. Cramer, B. S. Covino, S. J. Bullard et al., "Corrosion prevention and remediation strategies for reinforced concrete coastal bridges," Cement and Concrete Composites, vol. 24, no. 1, pp. 101-117, 2002.

[5] M. C. García-Alonso, M. L. Escudero, J. M. Miranda et al., "Corrosion behaviour of new stainless steels reinforcing bars embedded in concrete," Cement and Concrete Research, vol. 37, no. 10, pp. 1463-1471, 2007.

[6] E. Briz, M. V. Biezma, and D. M. Bastidas, "Stress corrosion cracking of new 2001 lean-duplex stainless steel reinforcements in chloride contained concrete pore solution: an electrochemical study," Construction and Building Materials, vol. 192, pp. 1-8, 2018.

[7] J. O. Rivera-Corral, G. Fajardo, G. Arliguie, R. Orozco-Cruz, F. Deby, and P. Valdez, "Corrosion behavior of steel reinforcement bars embedded in concrete exposed to chlorides: effect of surface finish," Construction and Building Materials, vol. 147, pp. 815-826, 2017.

[8] M. C. Alonso, F. J. Luna, and M. Criado, "Corrosion behavior of duplex stainless steel reinforcement in ternary binder concrete exposed to natural chloride penetration," Construction and Building Materials, vol. 199, pp. 385-395, 2019.

[9] I. G. Ogunsanya and C. M. Hansson, "The semiconductor properties of passive films and corrosion behavior of stainless 
steel reinforcing bars in simulated concrete pore solution," Materialia, vol. 6, Article ID 100321, 2019.

[10] E. Medina, A. Cobo, and D. M. Bastidas, "Evaluation of structural behaviour and corrosion resistant of austenitic AISI 304 and duplex AISI 2304 stainless steel reinforcements embedded in ordinary Portland cement mortars," Revista de Metalurgia, vol. 48, no. 6, pp. 445-458, 2012.

[11] M. Liu, S. Fan, R. Ding, G. Chen, E. Du, and K. Wang, "Experimental investigation on the fire resistance of restrained stainless steel H-section columns," Journal of Constructional Steel Research, vol. 163, Article ID 105770, 2019.

[12] M. Gastaldi and L. Bertolini, "Effect of temperature on the corrosion behaviour of low-nickel duplex stainless steel bars in concrete," Cement and Concrete Research, vol. 56, pp. 52-60, 2014.

[13] F. J. Carcel-Carrasco, M. Pascual-Guillamon, L. S. Garcia, F. S. Vicente, and M. A. Perez-Puig, "Pitting corrosion in AISI 304 rolled stainless steel welding at different deformation levels," Applied Sciences, vol. 9, no. 16, 2019.

[14] B. Zheng, G. Shu, and Q. Jiang, "Predictions of material properties in press-braked austenitic stainless steel sections," Journal of Constructional Steel Research, vol. 160, pp. 110-123, 2019.

[15] B. Zheng, G. Shu, and Q. Jiang, "Experimental study on residual stresses in cold rolled austenitic stainless steel hollow sections," Journal of Constructional Steel Research, vol. 152, pp. 94-104, 2019.

[16] L. Tang, A. Ince, and J. Zheng, "Numerical modeling of residual stresses and fatigue damage assessment of ultrasonic impact treated 304L stainless steel welded joints," Engineering Failure Analysis, vol. 108, Article ID 104277, 2019.

[17] L. Gardner and K. T. Ng, "Temperature development in structural stainless steel sections exposed to fire," Fire Safety Journal, vol. 41, no. 3, pp. 185-203, 2006.

[18] S. Jung, C. Jeon, Y. H. Jo et al., "Effects of tungsten and molybdenum on high-temperature tensile properties of five heat-resistant austenitic stainless steels," Materials Science and Engineering: A, vol. 656, pp. 190-199, 2016.

[19] Y. Liang, T. Manninen, O. Zhao, F. Walport, and L. Gardner, "Elevated temperature material properties of a new highchromium austenitic stainless steel," Journal of Constructional Steel Research, vol. 152, pp. 261-273, 2019.

[20] L. Mosecker, D. T. Pierce, A. Schwedt et al., "Temperature effect on deformation mechanisms and mechanical properties of a high manganese $\mathrm{C}+\mathrm{N}$ alloyed austenitic stainless steel," Materials Science and Engineering: A, vol. 642, pp. 71-83, 2015.

[21] C. Wang, C. Shen, Q. Cui, C. Zhang, and W. Xu, "Tensile property prediction by feature engineering guided machine learning in reduced activation ferritic/martensitic steels," Journal of Nuclear Materials, vol. 529, Article ID 151823, 2019.

[22] W. He, F. Li, H. Zhang, H. Chen, and H. Guo, "The influence of cold rolling deformation on tensile properties and microstructures of Mn18Cr18 N austenitic stainless steel," Materials Science and Engineering: A, vol. 764, p. 138245, 2019.

[23] Y. Shen and R. Chacon, "Effect of uncertainty in localized imperfection on the ultimate compressive strength of coldformed stainless steel hollow sections," Applied Sciences, vol. 9, no. 18, 2019.

[24] I. Calderon-Uriszar-Aldaca, E. Briz, P. Larrinaga, and H. Garcia, "Bonding strength of stainless steel rebars in concretes exposed to marine environments," Construction and Building Materials, vol. 172, pp. 125-133, 2018.
[25] D. Ertzibengoa, S. Matthys, and L. Taerwe, "Bond behaviour of flat stainless steel rebars in concrete," Materials and Structures, vol. 45, no. 11, pp. 1639-1653, 2012.

[26] D. Ertzibengoa, S. Matthys, and L. Taerwe, "Bond characteristics of carbon and stainless steel flat rebars with an alternate rib pattern," Materials and Structures, vol. 46, no. 7, pp. 1107-1121, 2013.

[27] M. F. Hassanein and N. Silvestre, "Flexural behavior of lean duplex stainless steel girders with slender unstiffened webs," Journal of Constructional Steel Research, vol. 85, pp. 12-23, 2013.

[28] R. Shamass and K. A. Cashell, "Analysis of stainless steelconcrete composite beams," Journal of Constructional Steel Research, vol. 152, pp. 132-142, 2019.

[29] M. Rabi, K. A. Cashell, and R. Shamass, "Flexural analysis and design of stainless steel reinforced concrete beams," Engineering Structures, vol. 198, p. 109432, 2019.

[30] GB50010-2010, Code for Design of Concrete Structures, Ministry of Housing and Urban-Rural Development of the People's Republic of China, Beijing, China, 2010.

[31] ACI 318-14, Building Code Requirements for Reinforced Concrete and Commentary, American Concrete Institute, Farmington Hills, MI, USA, 2014.

[32] GB/T 228-2002, Code for Design of Concrete Structures, General Administration of Quality Supervision, Inspection and Quarantine of the People's Republic of China, Beijing, China, 2002.

[33] W. Ramberg and W. R. Osgood, "Description of stress-strain curves by three parameters," Technical Note National Advisory Committee for Aeronautics, vol. 1943, no. 902, 1943.

[34] K. J. R. Rasmussen, "Full-range stress-strain curves for stainless steel alloys," Journal of Constructional Steel Research, vol. 59, no. 1, pp. 47-61, 2003. 